\title{
Drug Exposure and the Risk of Microscopic Colitis: A Critical Update
}

\author{
Alfredo J. Lucendo ${ }^{1,2}$
}

Published online: 18 January 2017

(c) The Author(s) 2017. This article is published with open access at Springerlink.com

\begin{abstract}
A variety of luminal antigens, including a wide range of drugs, have been associated with the still littleknown pathophysiology of microscopic colitis (MC), with variable evidence suggesting causality. This article aims to review the aspects related to drugs as potential triggers of MC; to discuss the most commonly identified associations between drugs and MC; and to analyze the limitations of the studies currently available. A literature search was performed in PubMed combining the search terms 'drug exposure', 'drug consumption', and 'risk factors' with 'microscopic colitis', 'lymphocytic colitis', and 'collagenous colitis', with no language restrictions. Reference lists of retrieved documents were also reviewed. A handful of case-control studies have demonstrated significant associations between some commonly used drugs and a higher risk of developing MC. No universally accepted criteria for establishing cause-effect relationships in adverse reactions to drugs are available, but several methods that can be applied to MC, can provide degrees of the likelihood of an association. A high probability imputation in the development of MC as a drug adverse effect has only been demonstrated for individual cases by applying chronological (challenge, de-challenge, and relapse with re-challenge) and semiological criteria. Several case-control studies have shown significant associations between exposure to drugs and $\mathrm{MC}$, but the variability in their
\end{abstract}

Alfredo J. Lucendo

ajlucendo@hotmail.com

1 Department of Gastroenterology, Hospital General de Tomelloso, Vereda de Socuéllamos s/n, Tomelloso, 13700 Ciudad Real, Spain

2 Centro de Investigación Biomédica en Red de Enfermedades Hepáticas y Digestivas (CIBERehd), Madrid, Spain design, the reference populations used, and the definitions for drug exposure considered require specific analyses. It can be concluded that drug exposure and MC as a likely cause-effect relationship has only been described for a handful of drugs and in individual cases.

\section{Key Points}

Several studies, mainly retrospective case-control studies, have associated microscopic colitis with exposure to some commonly used drugs.

Chronic diarrhea constitutes the main clinical presentation of microscopic colitis, and may appear as a common side effect of multiple drugs.

A certain cause-effect relationship between drug exposure and microscopic colitis has only been described in a handful of drugs and in individual cases, with additional evidence suggesting that drugs are not involved in the majority of microscopic colitis cases.

\section{Introduction}

The term microscopic colitis (MC) brings together a family of chronic inflammatory bowel diseases, including the principal entities of lymphocytic colitis (LC) and collagenous colitis (CC). Both are characterized by chronic or intermittent watery diarrhea, a normal or near-normal aspect of the colon in colonoscopy, and specific 
abnormalities in biopsies obtained from the colonic mucosa that distinguish an entity separate from any other [1-3]: While both LC and CC share chronic inflammation in the lamina propria, an infiltration by more than 20 intraepithelial lymphocytes per 100 epithelial cells is required to warrant a diagnosis of LC. The key histological feature of $\mathrm{CC}$ is a broad subepithelial fibrous band $>10 \mu \mathrm{m}$ in thickness, immediately underneath the surface epithelium [2].

Since the characterization of the disease during the 1970s and 1980s [4-8], the incidence and prevalence of MC have developed from being a rare disorder to becoming a common cause for watery chronic diarrhea in our environment. A recent meta-analysis of epidemiological studies has shown an overall incidence rate for CC of 4.14 [95\% confidence interval (CI) 2.89-5.40] new cases per 100,000 inhabitants per year, and for LC of $4.85(95 \% \mathrm{CI}$ 3.45-6.25) [9]. Up to $10 \%$ of patients currently investigated because of watery non-bloody chronic diarrhea are diagnosed as MC, reaching $20 \%$ in subjects aged over 70 years, and being especially prevalent in older women and smokers [2]. A significant diagnostic overlap between diarrhea-dominant functional bowel disorders and MC has been recognized, with up to $10 \%$ of patients with irritable bowel syndrome truly presenting with MC [10].

Despite its relative frequency, the etiology of MC remains unknown [11]. The most common theories propose that $\mathrm{MC}$ results from the activation of the immune system in the colonic mucosa in response to exposure to different luminal antigenic factors [12], such as toxins, infections, bile acids, or drugs. In fact, the resolution of histopathological changes after bypassing mucosal intestinal transit suggests that luminal antigens are directly involved in the pathogenesis of MC [13-15]. It has recently been demonstrated that human leukocyte antigen-related immune mechanisms contribute to the dysregulated inflammation characterizing the disease [16, 17].

The potential infectious etiology for MC is based on several clinical observations, including the development of MC after an intestinal infection by Clostridium difficile $[18,19]$ or the higher frequency of antibodies against Yersinia enterocolitica and other infectious agents in the sera of CC patients compared with control subjects [20]. However, a specific pathogen has not been identified in patients with MC so far.

The potential effect of bile acids in the development of $\mathrm{MC}$ has been based on experimental models of the disease in animals [12, 22], the frequent appearance of diarrhea with bile acid malabsorption after an ileal resection [23], and the demonstration that there is malabsorption in a significant proportion of patients with LC and CC [24, 25]. Despite these factors, there is no conclusive scientific evidence on the etiological role of bile acids in $\mathrm{MC}$, and treatment with bile acid sequestrants do not result in remission of histological lesions in these patients [26].

The concept that some drugs could cause or worsen MC was initially proposed in the early 1990s [27, 28]. As a consequence, drug consumption has been repeatedly considered as an environmental risk factor involved in triggering or precipitating MC. A range of evidence, from individual case reports to clinical cases and even observational epidemiological studies, have implicated several frequently used drugs as potential causes of LC and CC, after documenting significant associations between the two phenomena. The recent American Gastroenterological Institute Guidelines for the management of $\mathrm{MC}$ in fact considers several drugs, including non-steroidal anti-inflammatory drugs (NSAIDs), aspirin, proton pump inhibitors (PPIs), selective serotonin reuptake inhibitors (SSRIs), clozapine, and acarbose as precipitating causes for $\mathrm{MC}$ [29]. However, the degree of cause-effect plausibility on which these observations are supported is widely variable [30].

Moreover, it is essential to consider that diarrhea is a common side effect of many medications, accounting for up to $7 \%$ of overall drug adverse events, triggered through different pathophysiological mechanisms, which are often multi-factorial [31-33]. More than 700 drugs have been recognized as a potential cause of diarrhea. These drugs also commonly affect elderly patients [34] because of their increased susceptibility to the toxic effects; metabolism inherent in the aging process, and the polypharmacy to which this population is subjected. This group of patients is the most likely to suffer from MC according to the majority of available epidemiological studies.

This review aims to analyze in depth the aspects related to the use of drugs as a potential cause of $\mathrm{MC}$, presenting the most commonly identified associations with $\mathrm{MC}$, and discussing the limitations of the available studies focused on this association. A search was conducted in PubMed on the association of MC and drug consumption, by combining the terms 'drug exposure' OR 'drug consumption' OR 'risk factors' with 'microscopic colitis' OR 'lymphocytic colitis' OR 'collagenous colitis'. All papers were included from the origin of records up to May 2016, with no restriction on language or publication time. Reference lists of retrieved documents were also reviewed to find additional information.

\section{Causal Relationships Between Drug Exposure and Adverse Effects: Criteria and Limitations}

Cause-effect relationships between exposure to a specific drug and the development of an adverse effect have been analyzed using a range of methods, but universally 
accepted criteria are currently lacking [35]. These methods can be grouped into three different categories: (1) expert judgment based on global insights; (2) algorithms, and (3) Bayesian or probabilistic methods.

The World Health Organization program for international drug monitoring has proposed a system based on the expert judgment $[36,37]$ method, in which different categories of causality are established based on (1) the temporal sequence and timing between cause and effect; (2) prior information on the drug; (3) the dose-response relationship; (4) the pattern of response to the drug; (5) the rechallenge (looking for a relapse event in administering the drug again); (6) the exclusion of other alternative etiologic candidates; and (7) exposure to concomitant drugs. With this system, adverse events are thus classified as 'certain', 'probable', 'possible', 'unlikely', and 'not assessable' (Table 1).

Algorithms use structured and standardized methods for evaluating possible adverse effects of drugs, using a systematic approach. While providing a higher level of consistency and reproducibility than previous methods, some points still require clinical judgment to reach a conclusion. Among the algorithms, the so-called 'French method' (owing to having been employed by regulatory agencies in this country) [38] has been used specifically to assess the imputability of drugs in the origin of MC [39] (Table 2). The method employs three chronological criteria (drug challenge, de-challenge, and re-challenge) and four semiological criteria (suggestive clinical signs; favoring factor; alternative non-drug-related explanation, and specific laboratory tests). The overall score from these seven criteria allows classification as 'likely', 'possible', and 'dubious'.

Agreement between the two methods for assessing the imputability of drugs on side effects, if any, has been demonstrated to be very low in a comparative study, with agreement degrees given between 61 and $17 \%$ for the different categories [78]. Finally, probabilistic methods to assess the causality of adverse reactions to drugs use the findings of a specific case to transform the prior probabilities in posterior probabilities by calculating likelihood ratios for each of the relevant elements of the case [79]. The main advantage of these methods is the possibility of simultaneously evaluating multiple potential causes, along with the possibility of automating the process.

\section{Association Between Drug Exposure and Development of MC}

Large prospective longitudinal studies analyzing the causal relationship between drug exposure and the risk of developing MC are lacking [3]. Currently available evidence on the ability of drugs to trigger MC comes from several sources. Knowledge of these is essential to accurately assess the risks of bias inherent in the design of the studies addressing this topic.

\subsection{Case Reports}

These descriptions include a limited number of patients, since the early 1990s, in whom several drugs have been repeatedly involved in the risk of developing MC [27-51]. Although the list of potential drugs is long, a certain causal likelihood (based on the temporal relationship between exposure and symptoms; resolution of clinical and pathological findings after drug withdrawal; and relapse after rechallenge) has only been demonstrated for a small number of drugs, including acarbose [40], NSAIDs [51], ranitidine [72], omeprazole [71], lansoprazole [67], ticlopinin [75], and venotonic drug Cyclo 3 Fort (Pierre Fabre Medicament, Paris, France) [80]. However, in some cases, the rechallenge assessment exclusively involved clinical relapse, without obtaining new colonic biopsies $[51,75]$.

\subsection{Case-Control Studies}

Both prospective and retrospective case-control studies have demonstrated an association between a higher chance

Table 1 Causality categories in adverse reactions to drugs (adapted from WHO) [35, 36]

\begin{tabular}{ll}
\hline Probability & Criteria \\
\hline Certain & $\begin{array}{c}\text { Compatible timing of the event relative to drug exposure and improvement of the symptoms after stopping the medication and } \\
\text { recurrence of the symptoms (and other morphological alterations, if required) on repeat exposure or other definite proof } \\
\text { Compatible timing of the event relative to drug exposure and improvement of the symptoms after stopping the medication and } \\
\text { the event is not attributable to the patient's clinical status }\end{array}$ \\
Probable & $\begin{array}{l}\text { Compatible timing of the event relative to drug exposure but the event could also be attributable to the patient's clinical status } \\
\text { Possible }\end{array}$ \\
Unlikely & $\begin{array}{l}\text { All reactions not fulfilling the aforementioned criteria } \\
\text { Unclassifiable }\end{array}$
\end{tabular}

WHO World Health Organization 
Table 2 Assessment of levels of probability with which different drugs can trigger microscopic colitis: review of the literature (amended from Beaugerie and Pardi) [40]

\begin{tabular}{|c|c|c|}
\hline $\begin{array}{l}\text { High likelihood to cause microscopic } \\
\text { colitis }\end{array}$ & $\begin{array}{l}\text { Intermediate likelihood to cause microscopic } \\
\text { colitis }\end{array}$ & Low likelihood to cause microscopic colitis \\
\hline Acarbose [40] & Carbamazepine [41-43] & Cimetidine [45] \\
\hline Aspirin and NSAIDs [46-51] & Celecoxib [52] & Gold salts [53] \\
\hline Clozapine [54] & Duloxetine [55] & Piascledine [56] \\
\hline Entocapone [57] & Fluvastatin [52] & Pembrolizumab [58] \\
\hline Flavonoids $^{\mathrm{a}}[39,52,59-62]$ & Flutamide $[53,63]$ & Topiramate [92] \\
\hline Lansoprazole [64-68] & Oxetorone $[69,70]$ & $\begin{array}{l}\text { Angiotensin-converting enzyme inhibitors } \\
\text { [86] }\end{array}$ \\
\hline Omeprazole/esomeprazole [71] & Modopar $^{\circledR}$ b $[73]$ & Bisphosphonates [34] \\
\hline Ranitidine [72] & Paroxetine [41] & Angiotensin II receptor blockers [52] \\
\hline Sertraline $[39,41,52]$ & Simvastatin [83] & $\beta$-Blockers $[34,52,86]$ \\
\hline Ticlopidine $[53,63,74-77]$ & Stalevo ${ }^{\circledR} \mathrm{b}$ & \\
\hline
\end{tabular}

a Venotonic drugs containing flavonoids (diosmine, rutine, and hesperidine)

${ }^{\mathrm{b}}$ Modopar $^{\circledR}$ is an antiparkinson drug containing levodopa and benseracide; Stalevo ${ }^{\circledR}$ is an antiparkinson drug containing carbidopa, levodopa, and entocapone

of MC (or any of its types) and exposition to a defined drug product, but they do not allow the establishment of causeeffect relationships (Table 3). However, the main benefit of these studies is that they proposed potential pharmacologic risk factors to be further investigated through causality tests.

The exposition to PPIs, especially omeprazole and lansoprazole, has been related to an overall increased risk of developing MC [81, 86, 87]. In fact, several observational studies have involved PPIs as the drugs with the main risk of prompting the development of MC [81, 83, 86, 87]. The association of MC with other active principles within the PPI family (including pantoprazole, rabeprazole, and esomeprazole) was specifically dispelled by a recent casecontrol study [87].

The association between exposure to PPIs and MC has been, in general, more intense and more frequently reported for CC than for LC [52, 82, 83], and for the most symptomatic forms of MC [88]. Continuous exposure to PPIs over a period of 4-12 months was associated with an increased risk of $\mathrm{MC}$; its prolonged and continuous use for more than 1 year reduced this risk. A cause-effect relationship between the dose of PPIs and the risk of developing MC has not been demonstrated [87].

Histamine-2 receptor antagonist drugs have been involved in the increased risk of presenting $\mathrm{MC}$ in individual case reports [72] and also in case-control studies [87]. This leads us to consider that, beyond the molecule's own effect in prompting $\mathrm{MC}$, its pharmacological effect by inhibiting acid secretion and raising gastric $\mathrm{pH}$ might also be related to the development of MC, either by increasing the permeability and altering the function of the intestinal barrier [89] or by modifying the intestinal microbiota composition [90].
Exposure to NSAIDs (in general), including aspirin at low doses $(<300 \mathrm{mg}$ daily), has been linked with an increased risk of $\mathrm{MC}$ in each of its two $\mathrm{CL}$ and $\mathrm{CC}$ variants, in six studies [34, 52, 82, 83, 86, 87]. Experimental studies support a pathogenic role for NSAIDs and aspirin on the intestinal barrier, over both the mucous layer and enterocytes, leading to dysfunction and increased intestinal permeability followed by enhanced exposure to luminal triggers and acute inflammation [91]. This association, however, has not been universally reproduced in other similarly designed research [92]. Furthermore, concomitantly using NSAIDs with PPIs (two drugs that are frequently prescribed in combination) compared with each of these drugs separately has been shown to increase the risk of MC according to a recent case-control study [87].

A link between the exposure to SSRIs, especially sertraline, and an increased risk of MC has been documented in several studies $[34,52,83]$, in patients with both CC and CL. Serotonin accelerates the intestinal motility and promotes water and electrolyte secretion, with a secondary compensatory increased expression in peptide YY, as observed in LC patients [21]. However, other studies have not shown this association [87].

Studies have associated, though not universally [85], MC with exposure to statins [34, 83, 87], $\beta$-blockers $[34,52,86]$, and biphosphonates [34]. Differences in the exposure to these drugs in MC patients and patients with chronic diarrhea were not demonstrated in another study [84], suggesting that these drugs could behave like diarrhea inducers instead of true triggers of MC. Less frequently, significant associations between MC and the use of angiotensin-converting enzyme inhibitors [86], angiotensin 


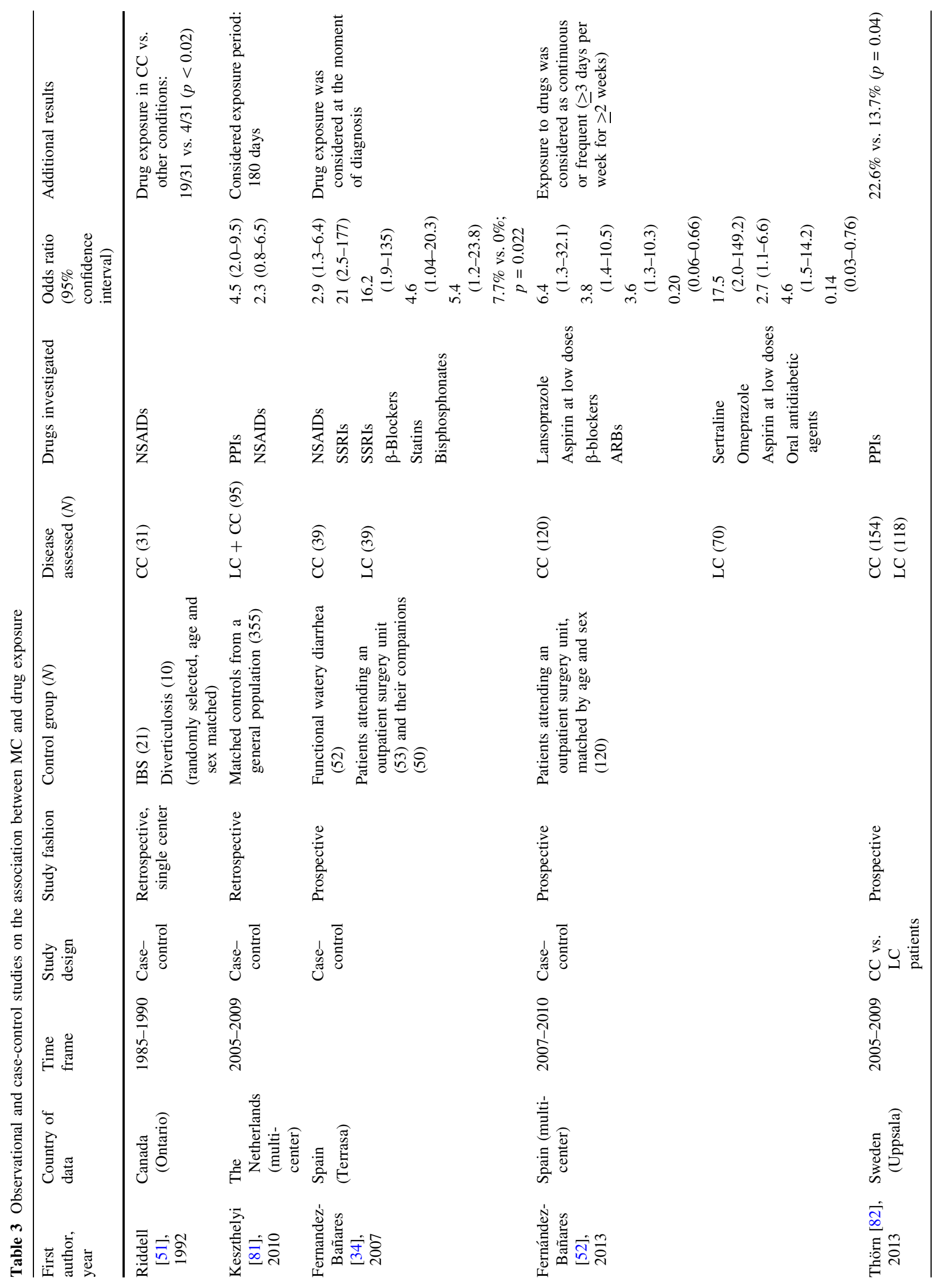




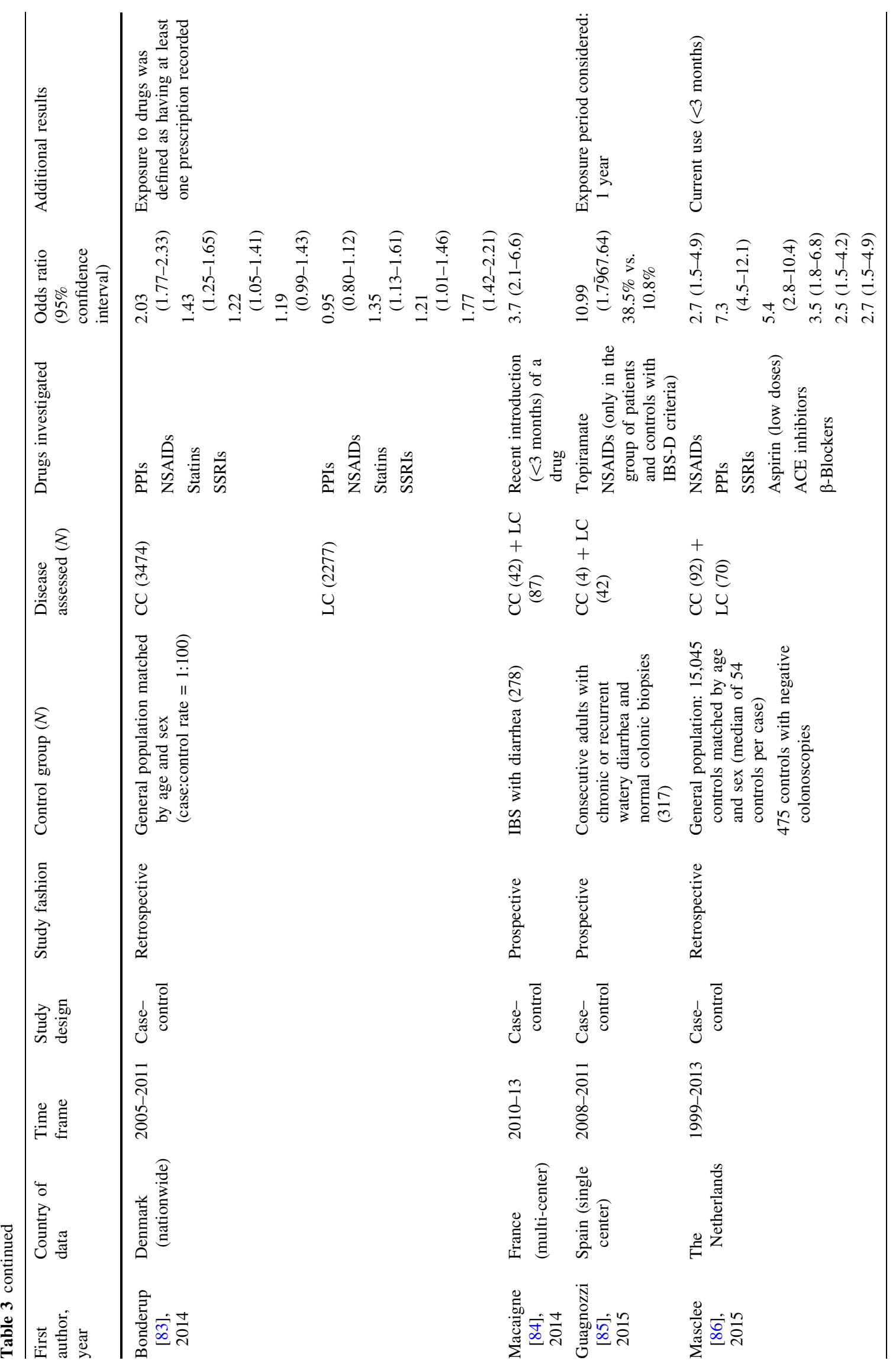




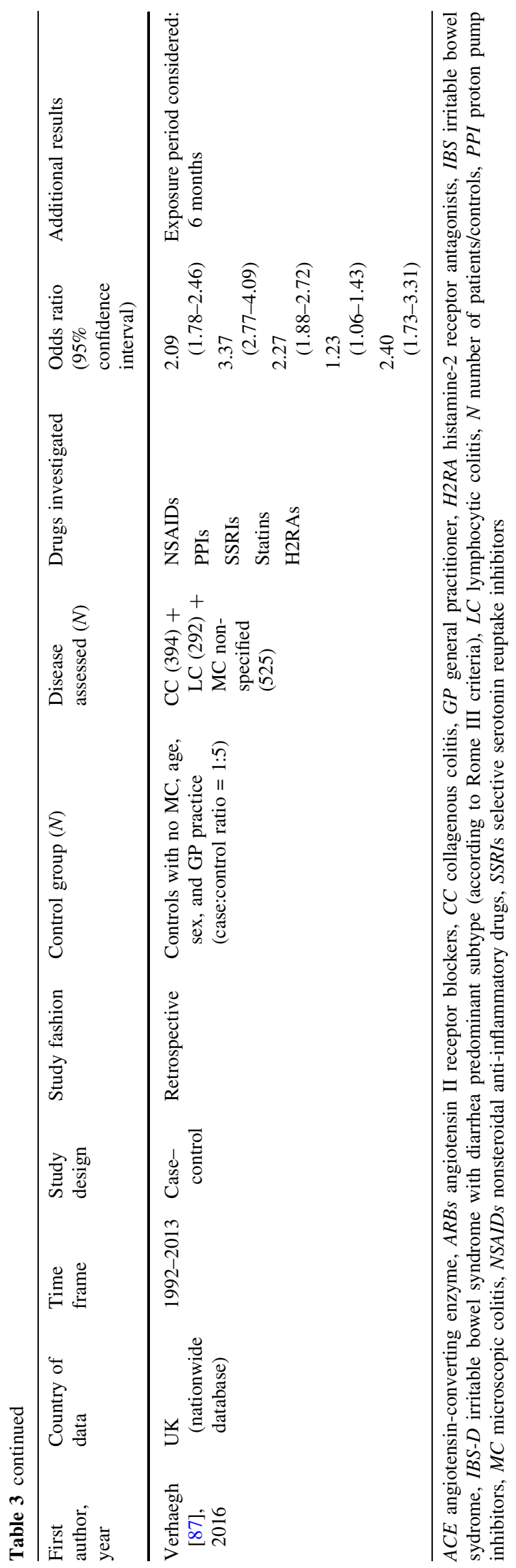

II receptor blockers [52] and, recently, topiramate [92] have been also reported.

The recent introduction of a new drug (within the last 3 months) has been identified as a significant risk factor associated with MC [84, 87], especially in the case of PPIs, NSAIDs, SSRIs, or anti-Parkinson drugs, compared with never having taken the drug, or having taken it in the past. In this regard, the induction of diarrhea or its deterioration after exposure to drugs may also encourage a colonoscopy examination to facilitate the diagnosis of an underlying MC, which would not necessarily be directly caused by the drug. In contrast, the exposure time to drugs specifically associated with MC was identified in another study [52] as being generally long (15-60 months).

\subsection{Drug Prescription Records}

The two case-control studies available based on this methodology yielded opposing results. While a large Danish national study including 5751 patients diagnosed with CC or CL found a significant association with PPI, statin, NSAID, and SSRI prescriptions [83], research carried out in Pennsylvania (USA) found no association between MC and the prescribing of several drugs commonly related with MC [93]. However, the degree of concordance between the consumption of drugs declared by patients and the data recorded on the database was generally low.

\section{Effect of the Dose of Drugs on the Risk of MC}

Despite some case-control studies having shown that low doses of aspirin were associated with an increased risk of MC in its two types [52, 86], the differential effect that increasing doses of a drug might have on the risk of developing $\mathrm{MC}$ has not been evaluated until very recently. A study based on a large database of longitudinal records of clinical information [87] stratified patients in regard to the dose of drugs prescribed, following defined daily doses according to World Health Organization criteria. Differences in the risk of developing MC (expressed as odds ratios) were not demonstrated between patients who received $<0.75,0.75-1.25$, and $>1.25$ defined daily doses of NSAIDs, PPIs, SSRIs, or statins.

\section{Limitations and Bias of Studies on the Association Between Drugs and MC}

It is certainly possible that exposure to certain drugs might induce changes in susceptible individuals, leading them to trigger or enhance inflammatory changes in the colonic mucosa. However, many of the drugs, the use of which has 
Table 4 Frequency of drugs causing diarrhea (taken from Abraham et al. 2012 [32], reproduced with permission from Elsevier)

\begin{tabular}{|c|c|c|}
\hline Drugs that cause diarrhea in $\geq 20 \%$ of patients & Drugs that cause diarrhea in $\geq 10 \%$ of patients & Drugs that occasionally cause diarrhea \\
\hline$\alpha$-Glucosidase inhibitors & Antibiotics & 5-Aminosalicylates (especially olsalazine) \\
\hline Biguanides & Chemotherapeutic agents & Acetylcholinesterase inhibitors \\
\hline Auronafin (gold salt) & Cholinergic drugs & Anticholinergics \\
\hline Colchicine & Cisapride (off the market) & Caffeine \\
\hline Diacerein & Digoxin & Calcitonin \\
\hline Highly active antiretroviral therapy & Immunosuppressive agents & Carbamazepine \\
\hline Prostaglandins & Metoclopramide & Chenodeoxycholic acid \\
\hline \multirow[t]{22}{*}{ Tyrosine kinase inhibitors } & Orlistat (lipase inhibitor) & Cholestyramine \\
\hline & Osmotic laxatives & Cholinesterase inhibitors \\
\hline & Poorly or non-absorbable carbohydrates & Cimetidine \\
\hline & Selective serotonin reuptake inhibitors & Ferrous sulfate preparations (rare) \\
\hline & & Flavonoid-related veinotonic agents \\
\hline & & HMG-CoA reductase inhibitors \\
\hline & & Irinotecan \\
\hline & & Isotretinoin \\
\hline & & Levodopa-benserazide \\
\hline & & Magnesium antacids \\
\hline & & Methyldopa \\
\hline & & Motilin agonists \\
\hline & & Non-steroidal anti-inflammatory drugs \\
\hline & & Octreotide \\
\hline & & Penicillamine \\
\hline & & Prebiotics \\
\hline & & Proton pump inhibitors \\
\hline & & Tacrine \\
\hline & & Tegaserod (off the market) \\
\hline & & Theophylline \\
\hline & & Thyroid hormones \\
\hline & & Ticlopidine \\
\hline
\end{tabular}

$H M G$-CoA 3-hydroxy-3-methylglutaryl-coenzyme A

been linked with MC induction, are, at the same time, well recognized as causing drug-induced diarrhea. These include gold salts, acarbose, ticlopidine, sertraline, and, less frequently, PPIs and NSAIDs [31, 94] (Table 4).

However, if we consider the widespread use of most of the drugs that have been related to MC onset, which represent some of the most consumed remedies in medicine, it is highly unlikely that exposure to these drugs could constitute a major independent cause for this disease. It is also important to note that most MC patients lack a suggestive prior drug history, which rules out drugs and/or their metabolites as major etiological agents for this disease. Furthermore, only a small number of the reported associations between drugs and MC have been based on a certain probabilistic basis, based on World Health Organization proposed criteria [36] or on the French method for the assessment of causality in drug reactions [35].
Together with the limitations of establishing causal relationships, the criteria used to define 'exposure to drugs' varied widely among different studies, ranging from the patient receiving at least one prescription in the previous year (without evidence about compliance) $[92,95]$, to in the previous 6 months [34]; current consumption (thus considered if drug exposure occurred within 3 months of the onset of symptoms) [86]; recent exposure (between 2 and 3 months prior to the date a MC diagnosis was established) [87]; and to continuous or frequent intake at least 3 days per week for 2 weeks or more [34-52]. The average exposure time to a given suspected drug before MC-compatible symptom onset has not been uniformly considered amongst the different studies. Thus, the study of imputability of Beaugerie and Pardi [39] displayed a wide range of times between drug exposure and the development of watery diarrhea, ranging from 1 day to 3 months, although the trend was towards a rapid onset of 
symptoms at a median of 4 days. A recent study that analyzed the effect of drug exposure timing on the risk of developing $\mathrm{MC}$ in patients receiving PPIs and NSAIDs showed a significantly increased risk among patients with current and/or recent exposure, compared with those with previous use of both drugs [87].

Finally, the case-control studies that have shown statistically significant associations between certain drugs and MC did so by considering different types of reference populations, from the general population [81, 83, 86, 87], to patients with irritable bowel syndrome [51, 70], functional watery diarrhea [34], or patients undergoing surgery [52].

\section{Diagnosis of MC in Drug-Exposed Patients: How to Proceed in Clinical Practice}

Despite mounting evidence involving different drugs in the origin or the aggravation of $\mathrm{MC}$, we cannot exclude completely that the association between the two entities represents no more than a chance finding, especially when the drugs less frequently involved are considered. Thus, taking into account that the population most likely to be diagnosed with $\mathrm{MC}$ is also the most exposed to drugs, defining how to proceed in clinical practice when a patient receiving 'risky' drugs is diagnosed with $\mathrm{MC}$ represents an especially relevant topic. In this regard, currently available recommendations are based on expert opinion because specific studies demonstrating the superiority of one strategy over the other are still lacking.

Owing to the fact that the drugs currently being taken by a patient and those recently introduced have been more closely related to the risk of developing MC [81, 87], a detailed review of the drug history for possible causative agents is essential in all patients with chronic watery diarrhea and a MC diagnosis. It is also advisable not to start a specific treatment for MC (budesonide, for example) until a pharmacological origin has been ruled out.

The initial measure should consist, therefore, in withdrawing the suspected drug (if unnecessary, dispensable, or of dubious efficacy); if the patient cannot do without it, the drug should be replaced by another of similar efficacy. The clinical response should be evaluated after 10-14 days, and if the patient reports a clinical improvement, the therapeutic strategy should consist in avoiding the suspected drug, and additional corticosteroid-based treatment. Unfortunately, the publications having reported on the effect of such drug withdrawal on clinical manifestations of MC are still very limited [71, 96]. In the event that withdrawing or replacing the drug is not justified for medical reasons, it is advisable to start a specific budesonide-based treatment as in patients with non-drug-induced MC.

\section{Conclusions}

Diarrhea is a common side effect of multiple drugs appearing via a range of causes. Several studies, mainly retrospective case-control studies, have associated $\mathrm{MC}$ with exposure to some commonly used drugs. However, this result cannot unequivocally be the cause-effect relationship in all cases, but rather provides new research avenues around the associations described. A certain cause-effect relationship between drug exposure and $\mathrm{MC}$ has only been described in a handful of drugs and in individual cases.

\section{Compliance with Ethical Standards}

Funding No specific funding was required to carry out the research included in this article.

Conflict of interest The author has no conflicts of interest in this work.

Open Access This article is distributed under the terms of the Creative Commons Attribution-NonCommercial 4.0 International License (http://creativecommons.org/licenses/by-nc/4.0/), which permits any noncommercial use, distribution, and reproduction in any medium, provided you give appropriate credit to the original author(s) and the source, provide a link to the Creative Commons license, and indicate if changes were made.

\section{References}

1. Jawhari A, Talbot IC. Microscopic, lymphocytic and collagenous colitis. Histopathology. 1996;29:101-10.

2. Munch A, Aust D, Bohr J, et al. Microscopic colitis: current status, present and future challenges: statements of the European Microscopic Colitis Group. J Crohns Colitis. 2012;6:932-45.

3. Fernandez-Banares F, Casanova MJ, Arguedas Y, et al. Current concepts on microscopic colitis: evidence-based statements and recommendations of the Spanish Microscopic Colitis Group. Aliment Pharmacol Ther. 2016;43:400-26.

4. Lindstrom CG. "Collagenous colitis" with watery diarrhoea: a new entity? Pathol Eur. 1976;11:87-9.

5. Freeman H, Weinstein WST. Watery diarrhea syndrome associated with a lesion of the colonic basement membrane (BM)lamina propria (LP) interface. Ann R Coll Phys Surg Can. 1976;9:A45.

6. Lazenby AJ, Yardley JH, Giardiello FM, et al. Lymphocytic ("microscopic") colitis: a comparative histopathologic study with particular reference to collagenous colitis. Hum Pathol. 1989;20:18-28.

7. Gu J, Stocchi L, Remzi F, Kiran RP. Factors associated with postoperative morbidity, reoperation and readmission rates after laparoscopic total abdominal colectomy for ulcerative colitis. Colorectal Dis. 2013;15:1123-9.

8. Read NW, Krejs GJ, Read MG, et al. Chronic diarrhea of unknown origin. Gastroenterology. 1980;78(2):264-71.

9. Tong J, Zheng Q, Zhang C, et al. Incidence, prevalence, and temporal trends of microscopic colitis: a systematic review and meta-analysis. Am J Gastroenterol. 2015;110(2):265-76 (quiz 277). 
10. Guagnozzi D, Arias A, Lucendo AJ. Systematic review with meta-analysis: diagnostic overlap of microscopic colitis and functional bowel disorders. Aliment Pharmacol Ther. 2016. doi:10.1111/apt.13573.

11. Guagnozzi D, Lucendo AJ. Advances in knowledge on microscopic colitis: from bench to bedside. Rev Esp Enferm Dig. 2015;107:98-108.

12. Pisani LF, Tontini GE, Vecchi M, Pastorelli L. Microscopic colitis: what do we know about pathogenesis? Inflamm Bowel Dis. 2016;22:450-8.

13. Veress B, Lofberg R, Bergman L. Microscopic colitis syndrome. Gut. 1995;36:880-6.

14. Jarnerot G, Tysk C, Bohr J, Eriksson S. Collagenous colitis and fecal stream diversion. Gastroenterology. 1995;109:449-55.

15. Bohr J, Tysk C, Eriksson S, et al. Collagenous colitis: a retrospective study of clinical presentation and treatment in 163 patients. Gut. 1996;39:846-51.

16. Westerlind H, Mellander MR, Bresso F, et al. Dense genotyping of immune-related loci identifies HLA variants associated with increased risk of collagenous colitis. Gut. 2015;. doi:10.1136/ gutjnl-2015-309934.

17. Westerlind H, Bonfiglio F, Mellander MR, et al. HLA associations distinguish collagenous from lymphocytic colitis. Am J Gastroenterol. 2016;111:1211-3.

18. Walter SA, Munch A, Ost A, Strom M. Anorectal function in patients with collagenous colitis in active and clinically quiescent phase, in comparison with healthy controls. Neurogastroenterol Motil. 2010;22(534-8):e118.

19. Erim T, Alazmi WM, O'Loughlin CJ, Barkin JS. Collagenous colitis associated with Clostridium difficile: a cause effect? Dig Dis Sci. 2003;48:1374-5.

20. Bohr J, Nordfelth R, Jarnerot G, Tysk C. Yersinia species in collagenous colitis: a serologic study. Scand J Gastroenterol. 2002;37:711-4.

21. El-Salhy M, Gundersen D, Hatlebakk JG, Hausken T. Clinical presentation, diagnosis, pathogenesis and treatment options for lymphocytic colitis (review). Int J Mol Med. 2013;32:263-70.

22. Breuer NF, Rampton DS, Tammar A, et al. Effect of colonic perfusion with sulfated and nonsulfated bile acids on mucosal structure and function in the rat. Gastroenterology. 1983;84:969-77.

23. Lewis FW, Warren GH, Goff JS. Collagenous colitis with involvement of terminal ileum. Dig Dis Sci. 1991;36:1161-3.

24. Ingle SB, Adgaonkar BD, Ingle CRH. Microscopic colitis: common cause of unexplained nonbloody diarrhea. World $\mathrm{J}$ Gastrointest Pathophysiol. 2014;5:48-53.

25. Fernandez-Banares F, Esteve M, Salas A, et al. Bile acid malabsorption in microscopic colitis and in previously unexplained functional chronic diarrhea. Dig Dis Sci. 2001;46:2231-8.

26. Ung KA, Kilander A, Nilsson O, Abrahamsson H. Long-term course in collagenous colitis and the impact of bile acid malabsorption and bile acid sequestrants on histopathology and clinical features. Scand J Gastroenterol. 2001;36:601-9.

27. Giardiello FM, Hansen FC 3rd, Lazenby AJ, et al. Collagenous colitis in setting of nonsteroidal antiinflammatory drugs and antibiotics. Dig Dis Sci. 1990;35:257-60.

28. Tanaka M, Mazzoleni G, Riddell RH. Distribution of collagenous colitis: utility of flexible sigmoidoscopy. Gut. 1992;33:65-70.

29. American Gastroenterological Association. AGA Institute Guideline on the management of microscopic colitis: clinical decision support tool. Gastroenterology. 2016;150:276.

30. Lucendo AJ, Fernández-Bañares F. Colitis microscópica y exposición a fármacos: una revisión crítica. EII al día. 2015;14:94-104.

31. Abraham BP, Sellin JH. Drug-induced, factitious, and idiopathic diarrhoea. Best Pract Res Clin Gastroenterol. 2012;26:633-48.
32. Chassany O, Michaux A, Bergman JF. Drug-induced diarrhoea. Drug Saf. 2000;22:53-72.

33. Pilotto A, Franceschi M, Vitale D, et al. The prevalence of diarrhea and its association with drug use in the elderly outpatients: a multicenter study. Am J Gastroenterol 2008;103:2816-23.

34. Fernandez-Banares F, Esteve M, Espinos JC, et al. Drug consumption and the risk of microscopic colitis. Am J Gastroenterol. 2007; 102:324-30.

35. Agbabiaka TB, Savovic J, Ernst E. Methods for causality assessment of adverse drug reactions: a systematic review. Drug Saf. 2008;31:21-37.

36. World Health Organization UMC. The use of the WHOUMC system for standardized case panel causality assessment. 2015. http://who-umc.org/graphics/24734.pdf. Accessed 7 Dec 2016.

37. Samaras D, Samaras N, Antonini P, et al. Determining drug causation from geriatric clinical observations: the case study of a suspected hypersensitivity vasculitis with glomerular involvement asociated with lansoprazole. Eur Geriatr Med. 2010;1:310-3.

38. Bégaud B, Evreux JC, Jouglard J, Lagier G. Unexpected or toxic drug reaction assessment (imputation): actualization of the method used in France. Therapie. 1985;40:111-8.

39. Beaugerie L, Pardi DS. Review article: drug-induced microscopic colitis: proposal for a scoring system and review of the literature. Aliment Pharmacol Ther. 2005;22:277-84.

40. Piche T, Raimondi V, Schneider S, et al. Acarbose and lymphocytic colitis. Lancet. 2000;356:1246.

41. Olesen M, Eriksson S, Bohr J, et al. Lymphocytic colitis: a retrospective clinical study of 199 Swedish patients. Gut. 2004;53:536-41.

42. Mahajan L, Wyllie R, Goldblum J. Lymphocytic colitis in a pediatric patient: a possible adverse reaction to carbamazepine. Am J Gastroenterol. 1997;92:2126-7.

43. Linares Torres P, Fidalgo Lopez I, Castanon Lopez A, Martinez Pinto Y. Lymphocytic colitis as a cause of chronic diarrhea: possible association with carbamazepine. Aten Primaria. 2000;25:366-7.

44. Alvarez-Perez P, Rubio-Nazabal E, Marey-Lopez J, et al. Lymphocytic colitis induced by carbamazepine. An Med Intern. 1984;2004(21):572-3.

45. Duncan HD, Talbot IC, Silk DB. Collagenous colitis and cimetidine. Eur J Gastroenterol Hepatol. 1997;9:819-20.

46. Yagi K, Nakamura A, Sekine A, Watanabe H. Nonsteroidal antiinflammatory drug-associated colitis with a histology of collagenous colitis. Endoscopy. 2001;33:629-32.

47. Kakar S, Pardi DS, Burgart LJ. Colonic ulcers accompanying collagenous colitis: implication of nonsteroidal anti-inflammatory drugs. Am J Gastroenterol. 2003;98:1834-7.

48. Mennecier D, Gros P, Bronstein JA. Chronic diarrhea due to lymphocytic colitis treated with piroxicam beta cyclodextrin. Presse Med. 1999;28:735-7.

49. Milman N, Kraag G. NSAID-induced collagenous colitis. J Rheumatol. 2010;37:2432-3.

50. Al-Ghamdi MY, Malatjalian DA, Veldhuyzen van Zanten S. Causation: recurrent collagenous colitis following repeated use of NSAIDs. Can J Gastroenterol. 2002;16:861-2.

51. Riddell RH, Tanaka M, Mazzoleni G. Non-steroidal anti-inflammatory drugs as a possible cause of collagenous colitis: a case-control study. Gut. 1992;33:683-6.

52. Fernandez-Banares F, de Sousa MR, Salas A, et al. Epidemiological risk factors in microscopic colitis: a prospective casecontrol study. Inflamm Bowel Dis. 2013;19:411-7.

53. Fernandez-Banares F, Salas A, Esteve M, et al. Collagenous and lymphocytic colitis. evaluation of clinical and histological 
features, response to treatment, and long-term follow-up. Am J Gastroenterol. 2003;98:340-7.

54. Pelizza L, Melegari M. Clozapine-induced microscopic colitis: a case report and review of the literature. J Clin Psychopharmacol. 2007;27:571-4.

55. Kusnik B, Stolte M. Lymphocytic colitis under treatment with duloxetine. Z Gastroenterol. 2010;48:693-5.

56. Macaigne G, Ozon N, Dikov D, et al. Piascledine-associated lymphocytic colitis. Gastroenterol Clin Biol. 2004;28:412-3.

57. Maroy B. Entocapone-related lymphocytic colitis. Gastroenterol Clin Biol. 2008;32:695-7.

58. Baroudjian B, Lourenco N, Pages C, et al. Anti-PD1-induced collagenous colitis in a melanoma patient. Melanoma Res. 2016;26:308-11.

59. Ouyahya F, Codjovi P, Machet MC, et al. Diarrhea induced by Cyclo 3 Fort and lymphocytic colitis. Gastroenterol Clin Biol. 1993;17:65-6.

60. Lim C, Macaigne G, Boivin J-F, et al. Stalevo-associated lymphocytic colitis. Gastroenterol Clin Biol. 2008;32:698-9.

61. Chuveau E, Prignet JM, Carloz E, et al. Colite lymphocytaire vraisemblablement imputable à la prise de vinvurnine (Cervoxan $^{\text {TM }}$ ). Gastroenterol Clin Biol. 1998;22:362.

62. Mennecier D, Thiolet C, Bredin C, et al. Lymphocytic colitis after ingestion of Rustacea flavonoid extract. Presse Med. 2001;30:1063.

63. Baert F, Wouters K, D'Haens G, et al. Lymphocytic colitis: a distinct clinical entity? A clinicopathological confrontation of lymphocytic and collagenous colitis. Gut. 1999;45:375-81.

64. Capurso G, Marignani M, Attilia F, et al. Lansoprazole-induced microscopic colitis: an increasing problem? Results of a prospecive case-series and systematic review of the literature. Dig Liver Dis. 2011;43:380-5.

65. Chande N, Driman DK. Microscopic colitis associated with lansoprazole: report of two cases and a review of the literature. Scand J Gastroenterol. 2007;42:530-3.

66. Mukherjee S. Diarrhea associated with lansoprazole. J Gastroenterol Hepatol. 2003;18:602-3.

67. Wilcox GM, Mattia A. Collagenous colitis associated with lansoprazole. J Clin Gastroenterol. 2002;34:164-6.

68. Thomson RD, Lestina LS, Bensen SP, et al. Lansoprazole-associated microscopic colitis: a case series. Am J Gastroenterol. 2002;97:2908-13.

69. Fathallah N, Chatti S, Azouz MM. Lymphocytic colitis associated with oxetorone consumption. Gastroenterol Clin Biol. 2010;34:154-5.

70. Macaigne G, Boivin J-F, Chayette C, et al. Oxetorone-associated lymphocytic colitis. Gastroenterol Clin Biol. 2002;26:537.

71. Wilcox GM, Mattia AR. Microscopic colitis associated with omeprazole and esomeprazole exposure. J Clin Gastroenterol. 2009;43:551-3.

72. Beaugerie L, Patey N, Brousse N. Ranitidine, diarrhoea, and lymphocytic colitis. Gut. 1995;37:708-11.

73. Rassiat E, Michiels C, Sgro C, et al. Lymphocytic colitis due to Modopar. Gastroenterol Clin Biol. 2000;24:852-3.

74. Berrebi D, Sautet A, Flejou JF, et al. Ticlopidine induced colitis: a histopathological study including apoptosis. J Clin Pathol. 1998;51:280-3.

75. Rosa I, Nahon S, Cohen C, et al. Ticlopidine-induced lymphocytic colitis. Ann Med Interne (Paris). 1999;150:437-9.

76. Feurle GE, Bartz KO, Schmitt-Graff A. Lymphocytic colitis, induced by ticlopidine. Z Gastroenterol. 1999;37:1105-8.

77. Brigot C, Courillon-Mallet A, Roucayrol AM, Cattan D. Lymphocytic colitis and ticlopidine. Gastroenterol Clin Biol. 1998;22:361-2.
78. Macedo AF, Marques FB, Ribeiro CF, Texeira F. Causality assessment of adverse drug reactions: comparison of the results obtained from published decisional algorithms and from the evaluations of an expert panel, according to different levels of imputability. J Clin Pharm Ther. 2003;28:137-43.

79. Hutchinson TA. Computerized Bayesian ADE assessment. Drug Inf J. 1991;25:235-41.

80. Beaugerie L, Luboinski J, Brousse N, et al. Drug induced lymphocytic colitis. Gut. 1994;35:426-8.

81. Keszthelyi D, Jansen SV, Schouten GA, et al. Proton pump inhibitor use is associated with an increased risk for microscopic colitis: a case-control study. Aliment Pharmacol Ther. 2010;32:1124-8.

82. Thorn M, Sjoberg D, Ekbom A, et al. Microscopic colitis in Uppsala health region, a population-based prospective study 2005-2009. Scand J Gastroenterol. 2013;48:825-30.

83. Bonderup OK, Fenger-Gron M, Wigh T, et al. Drug exposure and risk of microscopic colitis: a nationwide Danish case-control study with 5751 cases. Inflamm Bowel Dis. 2014;20:1702-7.

84. Macaigne G, Lahmek P, Locher C, et al. Microscopic colitis or functional bowel disease with diarrhea: a French prospective multicenter study. Am J Gastroenterol. 2014;109:1461-70.

85. Guagnozzi D, Lucendo AJ, Angueira-Lapena T, et al. Prevalence and incidence of microscopic colitis in patients with diarrhoea of unknown aetiology in a region in central Spain. Dig Liver Dis. 2012;44:384-8.

86. Masclee GMC, Coloma PM, Kuipers EJ, Sturkenboom MC. Increased risk of microscopic colitis with use of proton pump inhibitors and non-steroidal anti-inflammatory drugs. Am J Gastroenterol. 2015;110:749-59.

87. Verhaegh BPM, de Vries F, Masclee AAM, et al. High risk of drug-induced microscopic colitis with concomitant use of NSAIDs and proton pump inhibitors. Aliment Pharmacol Ther. 2016;43:1004-13.

88. Roth B, Bengtsson M, Ohlsson B. Diarrhoea is not the only symptom that needs to be treated in patients with microscopic colitis. Eur J Intern Med. 2013;24:573-8.

89. Mullin JM, Valenzano MC, Whitby M, et al. Esomeprazole induces upper gastrointestinal tract transmucosal permeability increase. Aliment Pharmacol Ther. 2008;28:1317-25.

90. Imhann F, Bonder MJ, Vich Vila A, et al. Proton pump inhibitors affect the gut microbiome. Gut. 2016;65:740-8.

91. Pavlidis P, Bjarnason I. Aspirin induced adverse effects in the small and large intestine. Curr Pharm Des. 2015;21:5089-93.

92. Guagnozzi D, Lucendo AJ, Angueira T, et al. Drug consumption and additional risk factors associated with microscopic colitis: case-control study. Rev Esp Enferm Dig. 2015;107:347-53.

93. Pascua MF, Kedia P, Weiner MG, et al. Microscopic colitis and medication use. Clin Med Insights Gastroenterol. 2010;2010:11-9.

94. Abraham BP, Sellin J. Drug-induced diarrhea. In: Guandalini S, $\mathrm{VH}$, editor. Diarrhea, clinical gastroenterology. Springer Science+Business Media, LLC; 2011. p. 393-423.

95. Miehlke S, Hansen JB, Madisch A, et al. Risk factors for symptom relapse in collagenous colitis after withdrawal of shortterm budesonide therapy. Inflamm Bowel Dis. 2013;19:2763-7.

96. Yagi K, Endo S, Nakamura A, Sekine A. Clinical course of druginduced collagenous colitis and histological changes after drug withdrawal in a Japanese case series. Eur J Gastroenterol Hepatol. 2012;24:1105-9. 